\title{
To the question of the interpolation of the phase equilibrium curves for the hydrates of methane and carbon dioxide
}

\author{
Nail Musakaev ${ }^{1,2 *}$, and Stanislav Borodin ${ }^{1}$ \\ ${ }^{1}$ Tyumen Branch of Khristianovich Institute of Theoretical and Applied Mechanics of SB RAS, \\ 625026 Tyumen, Russia \\ ${ }^{2}$ Industrial University of Tyumen, 625000 Tyumen, Russia
}

\begin{abstract}
The experimental data base was developed. This database includes 200 points of the phase equilibrium curve of methane hydrate, as well as more than 300 experimental points for carbon dioxide hydrate. This database is based on the work of a large number of researchers. Taking into account the experimental data, empirical formulas are constructed for determining the equilibrium parameters of the methane and carbon dioxide hydrates, as well as the equilibrium curve of "liquid carbon dioxide gaseous carbon dioxide".
\end{abstract}

\section{Introduction}

Natural gas is one of the main energy carriers. For example, in 2014 it accounted for $21.6 \%$ of the global electricity production and its share continues growing [1,2], and the main component of natural gas is methane $(77-99 \%)$. The largest reserves of methane are concentrated in the methane hydrates. Their total volume $\left(\approx 20000\right.$ trillion $\left.\mathrm{m}^{3}\right)$ is two orders of magnitude higher than the volume of traditional recoverable methane reserves $\left(\sim 250\right.$ trillion $\left.\mathrm{m}^{3}\right)$. Given the increasing demand and the largest amount in comparison with the main types of fossil fuels, the methane produced from gas hydrates is the most promising source of energy.

The most likely cause of global warming is an increase in the concentration of greenhouse gases, in particular $\mathrm{CO}_{2}$. To combat this phenomenon it is necessary to take measures towards reducing the concentration of carbon dioxide by regularly removing $\mathrm{CO}_{2}$ from the atmosphere. One of such ways of the carbon dioxide utilization is its disposal in porous reservoirs in the gas hydrate form $[3,4,5]$.

To solve the above-described practical problems, a theoretical study is required, which also includes the construction of adequate empirical correlations of the phase equilibrium curves for the methane and carbon dioxide hydrates. The present paper is devoted to the construction of such relations taking into account two refinements. Firstly, the constructed empirical correlations show a good agreement with the experimental data at quadrupole points that is ensured by fixing these points during interpolation (at the remaining points the

${ }^{*}$ Corresponding author: musakaev@ikz.ru 
least squares method is applied). Secondly, they are continuous at quadrupole points that is necessary for the convergence of calculations near such points.

\section{The algorithm for constructing empirical formulas}

Figure 1 schematically shows the phase diagrams of the hydrates of methane (a) and carbon dioxide (b).
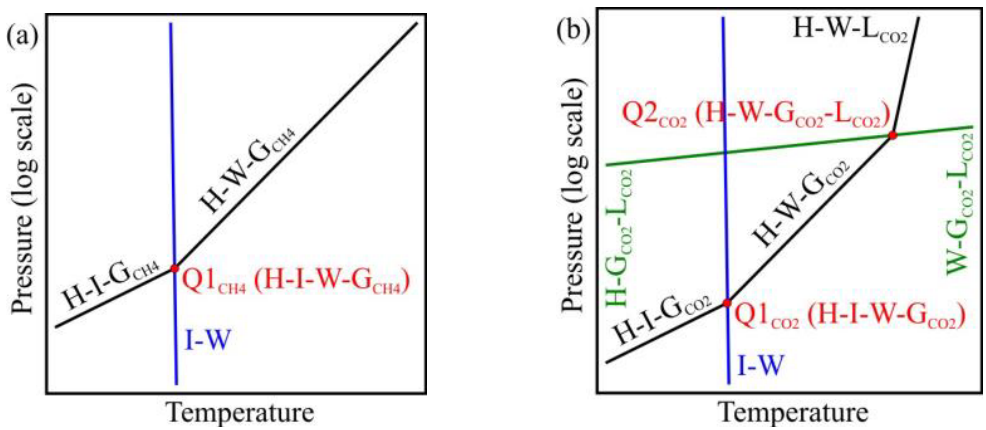

Fig. 1. Schematic representation of the phase equilibrium of methane (a) and carbon dioxide hydrates (b). H - hydrate, I - ice, W - liquid water, G - gas, L - liquid.

The empirical formulas will be constructed in the following form:

$$
\ln (p)=A_{0}+\frac{A_{1}}{T}+\frac{A_{2}}{T^{2}},
$$

where $p$ is the pressure; $T$ is the temperature; $A_{0}, A_{1}, A_{2}$ are the coefficients, which are determined from the following system of equations:

$$
\left\{\begin{array}{l}
A_{0}+\frac{A_{1}}{T_{\mathrm{Q}}}+\frac{A_{2}}{T_{\mathrm{Q}}^{2}}=\ln \left(p_{\mathrm{Q}}\right), \\
\sum_{i=1}^{N}\left[A_{1}\left(\frac{1}{T_{i}}-\frac{1}{T_{\mathrm{Q}}}\right)+A_{2}\left(\frac{1}{T_{i}^{2}}-\frac{1}{T_{\mathrm{Q}}^{2}}\right)+\ln \left(p_{\mathrm{Q}}\right)-\ln \left(p_{i}\right)\right]^{2} \rightarrow \min .
\end{array}\right.
$$

Here $T_{i}$ and $p_{i}$ are the experimental values of the temperature and pressure; $T_{\mathrm{Q}}$ and $p_{\mathrm{Q}}$ are the temperature and pressure in a quadrupole point.

The pressure and temperature values at the quadrupole points will be given based on the data of various authors available from [6]. In this case we take into account that the phase equilibrium temperature I-W is very weakly dependent on the pressure and that this curve must intersect with the phase curves for the hydrates at the points Q1. In the end we get:

$$
\begin{gathered}
T(p)_{\mathrm{I}-\mathrm{W}}=\text { const }=273 \mathrm{~K}(p \in[0.1,10] \mathrm{MPa}), \\
p_{\mathrm{Q} 1 \mathrm{CH} 4}=2.6 \mathrm{MPa}, \quad T_{\mathrm{Q} 1 \mathrm{CH} 4}=273 \mathrm{~K}, \\
p_{\mathrm{Q} 1 \mathrm{CO} 2}=1.2 \mathrm{MPa}, \quad T_{\mathrm{Q} 1 \mathrm{CO} 2}=273 \mathrm{~K}, \\
p_{\mathrm{Q} 2 \mathrm{CO} 2}=4.5 \mathrm{MPa}, \quad T_{\mathrm{Q} 2 \mathrm{CO} 2}=283 \mathrm{~K} .
\end{gathered}
$$


Using the described above method we find the curves for methane $\mathrm{H}-\mathrm{I}-\mathrm{G}_{\mathrm{CH} 4}, \mathrm{H}-\mathrm{W}-\mathrm{G}_{\mathrm{CH} 4}$ and for carbon dioxide $\mathrm{H}-\mathrm{I}-\mathrm{G}_{\mathrm{CO} 2}, \mathrm{H}-\mathrm{G}_{\mathrm{CO} 2}-\mathrm{L}_{\mathrm{CO} 2}, \mathrm{~W}-\mathrm{G}_{\mathrm{CO} 2}-\mathrm{L}_{\mathrm{CO} 2}$. To find the curve $\mathrm{H}-\mathrm{W}-\mathrm{G}_{\mathrm{CO} 2}$ we fix two points $\mathrm{Q} 1_{\mathrm{CO} 2}$ and $\mathrm{Q} 2_{\mathrm{CO} 2}$, and the coefficients of equation (1) are determined from the following system:

$$
\left\{\begin{array}{l}
A_{0}+\frac{A_{1}}{T_{\mathrm{Q} 1}}+\frac{A_{2}}{T_{\mathrm{Q} 1}^{2}}=\ln \left(p_{\mathrm{Q} 1}\right), \\
A_{2}=\frac{\left.\sum_{i=1}^{N}\left[\left(\ln \left(\frac{p_{i}}{p_{\mathrm{Q} 1}}\right)-\frac{\ln \left(p_{\mathrm{Q} 2} / p_{\mathrm{Q} 1}\right)}{T_{\mathrm{Q} 2}}+\frac{A_{2}}{T_{\mathrm{Q} 2}^{2}}=\ln \left(\frac{1}{T_{i}}-\frac{1}{T_{\mathrm{Q} 2}}\right)\right)\left(\frac{1}{T_{\mathrm{Q} 2}}\right), \frac{1}{T_{i}}\right)\left(\frac{1}{T_{\mathrm{Q} 1}}-\frac{1}{T_{\mathrm{Q} 2}}\right)\right]}{\sum_{i=1}^{N}\left[\left(\frac{1}{T_{i}}-\frac{1}{T_{\mathrm{Q} 1}}\right)\left(\frac{1}{T_{i}}-\frac{1}{T_{\mathrm{Q} 2}}\right)\right]^{2}} .
\end{array}\right.
$$

The empirical formula for the $\mathrm{H}-\mathrm{W}-\mathrm{G}_{\mathrm{CO} 2}$ curve in the form (1) does not correlate well with the experimental data, so for this curve we will use the following form:

$$
p=A_{0}+A_{1} T+A_{2} T^{2} .
$$

\section{The empirical formulas and their assessments}

Using the described above algorithm, we obtained the equations of the phase equilibrium curves. The coefficients $A_{0}, A_{1}$ and $A_{2}$ for these equations are presented in the Table 1 . To estimate the accuracy in the Table 1 , we also presented the coefficient of determination $\left(R^{2}\right)$, as well as the average $\left(\delta_{\mathrm{AV}}\right)$ and maximum $\left(\delta_{\mathrm{MAX}}\right)$ relative error over all points of the experimental data.

\begin{tabular}{|c|c|c|c|c|c|c|}
\hline Agent & Curve & $\begin{array}{c}\text { Temperature } \\
\text { interval, } \mathrm{K}\end{array}$ & Coefficients & $R^{2}$ & $\delta_{\mathrm{AV}}, \%$ & $\begin{array}{c}\delta_{\mathrm{MAX}}, \\
\%\end{array}$ \\
\hline \multirow{2}{*}{$\mathrm{CH}_{4}$} & H-I-G $\mathrm{G}_{\mathrm{CH} 4}$ & {$[178.2,273]$} & $\begin{array}{c}A_{0}=\ln (2.6)-A_{1} / 273-A_{2} / 273^{2} \\
A_{1}=-2768 \\
A_{2}=69900\end{array}$ & 0.9984 & 1.88 & 4.02 \\
\hline & $\mathrm{H}-\mathrm{W}-\mathrm{G}_{\mathrm{CH} 4}$ & {$[273,302]$} & $\begin{array}{c}A_{0}=\ln (2.6)-A_{1} / 273-A_{2} / 273^{2} \\
A_{1}=-61987 \\
A_{2}=7526200\end{array}$ & 0.9976 & 2.07 & 6.95 \\
\hline \multirow{5}{*}{$\mathrm{CO}_{2}$} & H-I-G $\mathrm{CO} 2_{\mathrm{C}}$ & {$[213.8,273]$} & $\begin{array}{c}A_{0}=\ln (1.2)-A_{1} / 273-A_{2} / 273^{2} \\
A_{1}=-13854 \\
A_{2}=1351500\end{array}$ & 0.9808 & 5.22 & 7.60 \\
\hline & $\mathrm{H}-\mathrm{W}-\mathrm{G}_{\mathrm{CO} 2}$ & {$[273,283]$} & $\begin{array}{c}A_{0}=\ln (1.2)-A_{1} / 273-A_{2} / 273^{2} ; \\
A_{1}=\ln (4.5 / 1.2) /(1 / 283-1 / 273)- \\
-A_{2} \cdot(1 / 283+1 / 273) ; \\
A_{2}=15000000\end{array}$ & 0.9804 & 3.26 & 11.46 \\
\hline & $\mathrm{H}-\mathrm{W}-\mathrm{L}_{\mathrm{CO} 2}$ & {$[283,292.7]$} & $\begin{array}{c}p=A_{0}+A_{1} \cdot T+A_{2} \cdot T^{2} \\
A_{0}=4.5-A_{1} \cdot 283-A_{2} \cdot 283^{2} \\
A_{1}=-815 \\
A_{2}=1.45\end{array}$ & 0.9930 & 13.80 & 45.45 \\
\hline & $\begin{array}{l}\mathrm{H}-\mathrm{G}_{\mathrm{CO} 2^{-}} \\
\mathrm{L}_{\mathrm{CO} 2}\end{array}$ & {$[256.5,283]$} & $\begin{array}{c}A_{0}=\ln (4.5)-A_{1} / 283-A_{2} / 283^{2} \\
A_{1}=-3478 \\
A_{2}=202500\end{array}$ & 0.9995 & 0.27 & 1.17 \\
\hline & $\begin{array}{c}\mathrm{W}-\mathrm{G}_{\mathrm{CO}^{-}} \\
\mathrm{L}_{\mathrm{CO} 2}\end{array}$ & {$[283,304]$} & $\begin{array}{c}A_{0}=\ln (4.5)-A_{1} / 283-A_{2} / 283^{2} \\
A_{1}=-6376 ; A_{2}=642700\end{array}$ & 0.9997 & 0.24 & 0.63 \\
\hline
\end{tabular}

Table 1. The coefficients for empirical formulas and their assessment. 
Fig. 2 shows the experimental data points and calculated phase curves for methane (a) and carbon dioxide (b).
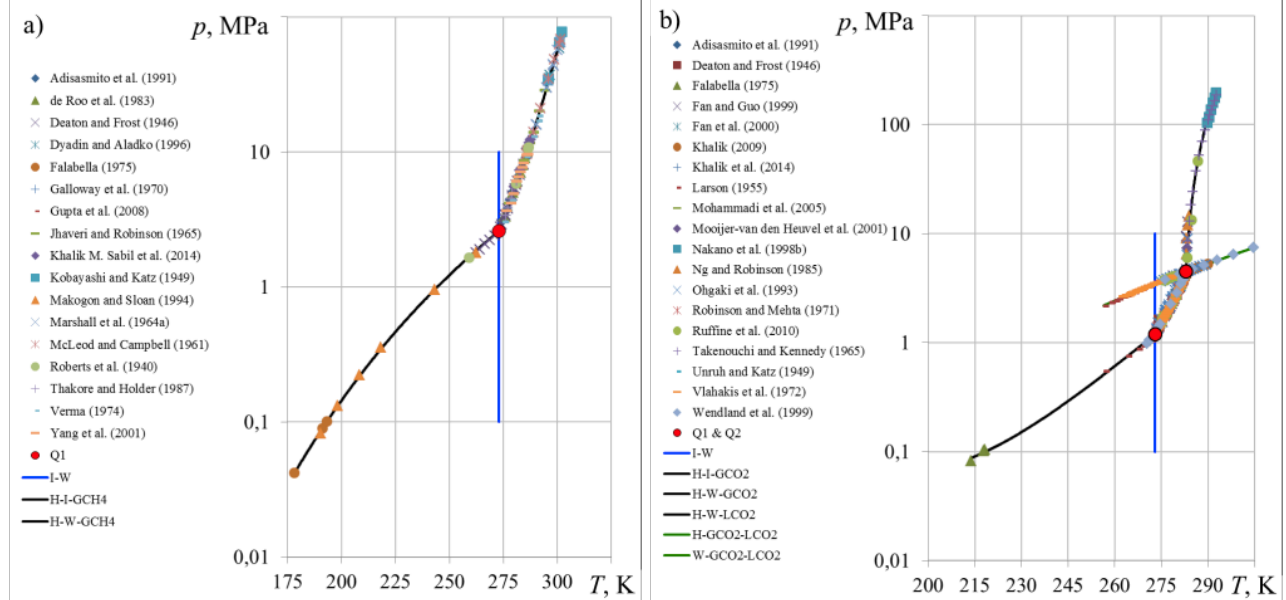

Fig. 2. The experimental data points and calculated curves for methane (a) and carbon dioxide (b).

In this work the empirical formulas for the determination of the equilibrium parameters of the methane and carbon dioxide hydrates, as well as the equilibrium curve of "liquid carbon dioxide - gaseous carbon dioxide", are constructed. The resulting curves intersect at quadrupole points, so that in the calculations there will be no problems with convergence due to discontinuities. At the same time good agreement with the experimental data was reached.

This work was supported by the Russian Foundation for Basic Research (project 17-51-540001).

\section{References}

1. Y.F. Makogon, S.A. Holditch, T.Y. Makogon, J. Petroleum Science and Eng. 56, 54 (2007)

2. Y.F. Makogon, J. Natural Gas Science and Eng. 2, 49 (2010)

3. G.G. Tsypkin, Fluid Dynamics 49, 789 (2014)

4. V.Sh. Shagapov, M.K. Khasanov, N.G. Musakaev, Ngoc Hai Duong, Int. J. Heat Mass Transfer 107, 1030 (2017)

5. G.K. Anderson, J. Chem. Thermodynamics 35, 1171 (2003)

6. E. Dendy Sloan, Carolyn A. Koh, Clathrate Hydrates of Natural Gases (CRC Press, Boca Raton, 2008) 